\title{
REVIEW
}

\section{NELL-1 in Genome-Wide Association Studies across Human Diseases}

\author{
Xu Cheng, ${ }^{{ }^{\dagger}}$ Jiayu Shi, ${ }^{\dagger}$ Zhonglin Jia, ${ }^{*}$ Pin Ha, ${ }^{\dagger}$ Chia Soo, ${ }^{\ddagger}$ Kang Ting, ${ }^{\S}$ Aaron W. James, ${ }^{\llbracket}$ Bing Shi, ${ }^{*}$ and Xinli Zhang
}

\begin{abstract}
From the State Key Laboratory of Oral Diseases, * National Clinical Research Centre for Oral Diseases, and the Department of Cleft Lip and Palate, West China Hospital of Stomatology, Sichuan University, Chengdu, China; the Section of Orthodontics, ${ }^{\dagger}$ Division of Growth and Development, School of Dentistry, and the Division of Plastic and Reconstructive Surgery, ${ }^{\ddagger}$ Department of Orthopaedic Surgery, Orthopaedic Hospital Research Center, University of California-Los Angeles, Los Angeles, California; the Forsyth Institute, ${ }^{\S}$ affiliate of the Harvard School of Dental Medicine, Boston, Massachusetts; and the Department of Pathology, "Johns Hopkins University School of Medicine, Baltimore, Maryland
\end{abstract}

\author{
Accepted for publication \\ November 24, 2021. \\ Address correspondence to \\ Bing Shi, Ph.D., M.D., No. 14, \\ Section 3, South Renmin Rd., \\ Wuhou District, Chengdu \\ 610041, China; or Xinli Zhang, \\ Ph.D., Center for the Health \\ Sciences 30-113, University of \\ California, Los Angeles, 10833 \\ Le Conte Ave., Los Angeles, \\ CA 90095. E-mail: \\ shibingcn1@126.com or \\ xzhang@dentistry.ucla.edu.
}

\begin{abstract}
Neural epidermal growth factor-like (EGFL)-like protein (NELL)-1 is a potent and key osteogenic factor in the development and regeneration of skeletal tissues. Intriguingly, accumulative data from genomewide association studies (GWASs) have started unveiling potential broader roles of NELL-1 beyond its functions in bone and cartilage. With exploration of the genetic variants of the entire genome in largescale disease cohorts, GWASs have been used for establishing the connection between specific singlenucleotide polymorphisms of NELL1, in addition to osteoporosis, metabolic diseases, inflammatory conditions, neuropsychiatric diseases, neurodegenerative disorders, and malignant tumors. This review summarizes the findings from GWASs on the manifestation, significance level, implications on function, and correlation of specific NELL1 single-nucleotide polymorphisms in various disorders in humans. By offering a unique and comprehensive correlation between genetic variants and plausible functions of NELL1 in GWASs, this review illustrates the wide range of potential effects of a single gene on the pathogenesis of multiple disorders in humans. (Am J Pathol 2022, 192: 395-405; https://doi.org/ 10.1016/j.ajpath.2021.11.006)
\end{abstract}

The genome-wide association study (GWAS) has been a useful method in medical and complex trait genomics for $>2$ decades. ${ }^{1}$ By probing into large-scale genetic variants across the genomes of many individuals, GWASs can shed light on novel genotype-phenotype associations. ${ }^{2}$ Results from GWASs contribute to an expanded knowledge of certain diseases, including, but not limited to, their causes, pathophysiology, and clinical treatment. ${ }^{3}$ Current interpretation of data from GWASs is typically focused on a single disease or trait and its multiple associated genes. However, studies focused on one specific gene of high frequency in multiple diseases or traits are lacking. This article reviews one specific gene, the gene that encodes neural epidermal growth factor-like (EGFL)-like protein (NELL)-1, the osteogenic capacity of which has been studied for $>2$ decades, by compilation of its diverging roles beyond its wellknown osteochondrogenic properties. ${ }^{4,5}$ This unique perspective can illustrate the potential complex implications of the functions of a single gene on multiple systems of the body, and shed light on the importance of a comprehensive understanding of genes and diseases at a systemic level. Clearly, NELL-1 is just one key element of the functional molecules in the extremely sophisticated networks involved in multiple conditions and treatments. The potential role of

\footnotetext{
Supported by NIH grants R01AR066782 (K.T.), R01AR068835 and R01AR061399 (C.S.), and R01DE029353 (C.S., X.Z.); UCLA/NIH CTSI grant UL1TR000124 (X.Z.); National Natural Science Foundation of China grant 81974147 (B.S.); National Natural Science Foundation of China grant 82001031 (X.C.); and West China School of Stomatology of Sichuan University grant RD-03-2020007 (B.S.).

Disclosures: X.Z., K.T., and C.S. are inventors of NELL1-related patents. X.Z., K.T., and C.S. are founders or former board members of Bone Biologics Inc./Bone Biologics Corp., which sublicenses Nell-1 patents from UC Regents, which also holds equity in the company. The authors declare no other potential conflicts of interest with respect to the authorship and publication of this article.
} 
NELL-1 is indeed worthy of further exploration, given the broader involvement of NELL1 in diseases and treatments revealed by GWASs.

\section{NELL1 Gene and the Identified Functions of the NELL-1 Protein}

$N E L L 1$ was named for its similarity to the gene $N E L$, which encodes EGFL protein. ${ }^{4}$ In humans, NELL1 has been mapped to chromosome 11 at $11 \mathrm{p} 15.1-\mathrm{p} 15.2$, spanning around $906 \mathrm{~kb}$, with 20 coding exons. ${ }^{4}$ NELL1 is highly conserved in humans and mice, with $95 \%$ nucleotide homology. ${ }^{6} N E L L 1$ encodes a cytoplasmic protein that has five EGFL repeats, in addition to a thrombospondin N-terminal domain, several von Willebrand factors, as well as histidinerich and cysteine-rich domains. ${ }^{7}$ NELL-1 protein has been reported to have several binding partners, such as protein kinase $\mathrm{C}$ (PKC) $\beta_{1}$, apoptosis-related protein 3 , and roundabout homolog $2 .^{5}$ These binding proteins are either nonspecific or not naturally present on the cell surface. ${ }^{8,9}$ However, recently, the physical high-affinity ligand receptor-like binding between NELL-1 and contactinassociated protein-like protein (Cntnap)-4 was identified, indicating Cntnap-4 as a specific NELL-1 receptor. ${ }^{10}$ Notably, NELL-1 protein has complex quaternary structures and several isoforms with distinct functions, ${ }^{5}$ potentially accounting for its functional diversity.

The functional role of NELL-1 began to be unraveled when the connection between NELL-1 expression and unilateral coronal craniosynostosis, a pathologic condition in humans, was established. ${ }^{7}$ Since then, a myriad of animal studies have explored the functions of NELL-1, starting with disease-model simulations of human nonsyndromic CS in Nell-1-overexpression transgenic mice. ${ }^{11}$ Continuous research efforts have attributed multiple roles to NELL-1 in physiologic and pathologic processes, which can be summarized as follows: i) NELL-1 is necessary in normal craniofacial and appendicular skeletogenesis and is a potent pro-osteogenic factor for osteochondral tissue regeneration $^{12-14}$; ii) NELL-1 exhibits anti-adipogenic effects when applied in bone-regeneration conditions ${ }^{14-16}$; iii) NELL-1 has therapeutic potential in osteoarthritis due to its pro-osteogenic and anti-inflammatory effects ${ }^{5,17}$; iv) NELL1 is a potential tumor-suppressing gene, on account of its involvement in promoter hypermethylation ${ }^{18,19}$; v) NELL-1 could play an important regulatory role in the nervous system due to its newly discovered receptor, Cntnap-4, which is crucial in synapse development ${ }^{5,10}$; and vi) NELL-1 serves as a podocyte antigen marker to define a distinct type of membranous nephropathy. ${ }^{20,21}$

\section{Genome-Wide Association Study of NELL1}

NELL1 gene has been a frequent hit in GWASs in a wide range of human diseases such as metabolic, neuropsychiatric, neurodegenerative, and inflammatory diseases, and cancers with susceptible gene loci spread throughout the NELL1 sequence (Figure 1). ${ }^{22-25}$ Some of these association studies have offered novel perspectives on the genuine susceptibility gene loci. ${ }^{22,23}$ Other association studies and corresponding function studies have verified the role of NELL-1 by highlighting the potential for combating the relevant disease using therapy. ${ }^{24,25}$ These gene loci are of genome-wide significance $\left(P<5 \times 10^{-8}\right),{ }^{3}$ suggestive significance $\left(P<5 \times 10^{-5}\right),{ }^{26}$ or nominal significance ${ }^{27}$ (Table 1$)$.

\section{Metabolic Diseases}

Given the established link of NELL-1 to craniosynostosis, the functional role of NELL-1 in bone-related disease has been thoroughly investigated. Despite the large number of animal studies in which the potential role of NELL-1 in bone regeneration was verified, ${ }^{10,11,13,14,17}$ a definite association is lacking in human studies. Nonetheless, some promising results have emerged from the connection between NELL1 and other metabolic diseases, such as lipid-metabolism disorders.

\section{Osteoporosis}

Osteoporosis is an aging-related bone-degenerative disease characterized by compromised bone strength and an increased risk for fracture. ${ }^{40,41}$ Genetic determinants in the progression of osteoporosis have been identified. ${ }^{40}$ Bone mineral density (BMD) is frequently used to predict osteoporotic fracture and remains the single best trait for the analysis of its prognosis. ${ }^{42}$ Previous GWASs have revealed $>20$ susceptible gene loci associated with a low BMD..$^{40,42}$

In the Framingham study, performed by Karasik et al, ${ }^{28}$ analysis of data from 2073 US patients showed that rs10766761, located in intron 12 of the NELL1 gene, was nominally associated with low BMD of both the femoral neck $\left(P=7.9 \times 10^{-4}\right)$ and the lumbar spine $\left(P=3.3 \times 10^{-4}\right)$. The study brought into perspective the different traits of osteoporosis and investigated the relationship between phenotype and the percentage of shared SNPs. NELL1 was among the 10 associated genes identified by more than one proxy for osteoporosis.

Acute lymphoblastic leukemia leads to bone loss in some affected patients, ${ }^{43}$ which can result either from the disease itself or from concomitant physical conditions. ${ }^{43}$ The BMD of lumbar vertebrae L1/L2 investigated in a study of the genetic risk factors for BMD loss in patients with acute lymphoblastic leukemia ${ }^{29}$ suggested NELL-1 as being significant for a decrease in BMD. ${ }^{29}$ Similarly, an SNP in intron 12 of NELL1, rs11025915, was found to be positively associated with BMD loss in patients with acute lymphoblastic leukemia.

Studies of the functions of NELL-1 in modulating osteogenesis have been underway for decades..$^{14,44-46}$ Systemic delivery of NELL-1 to mice with ovariectomy-induced 


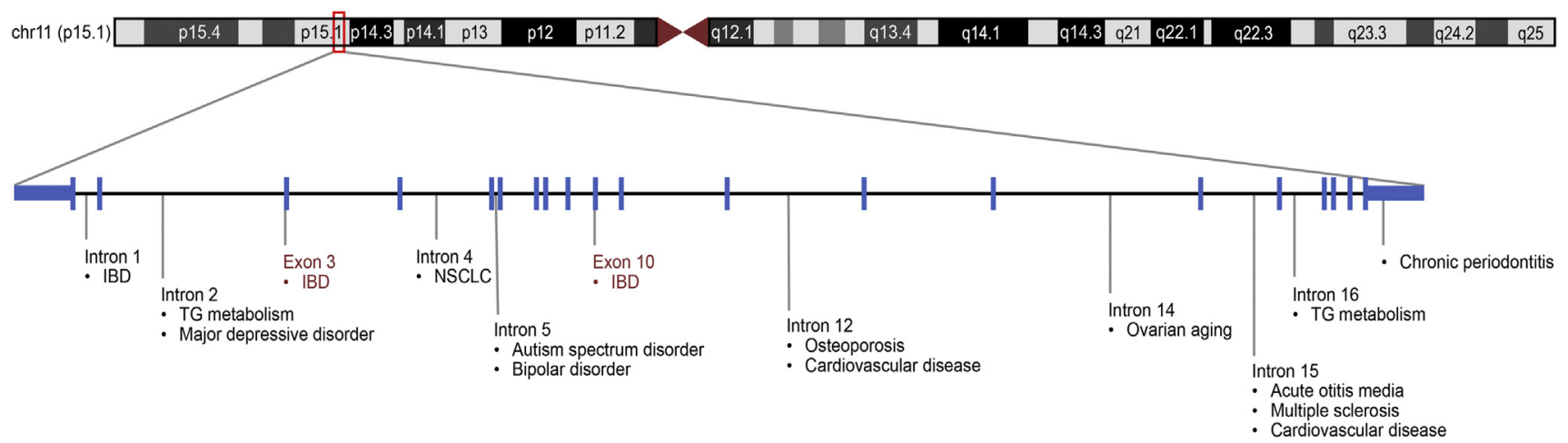

Figure 1 NELL1-related susceptible gene loci in human disorders. Boxed region indicates the region of NELL1 gene on chromosome 11. IBD, inflammatory bowel disease; NSCLC, non-small cell lung cancer; TG, triglyceride.

osteoporosis is associated with increased BMD, possibly by enhancement of the osteoblast differentiation and inhibition of the osteoclast-directed bone resorption. ${ }^{14}$ Similarly, in a sheep model of osteoporosis, local delivery of NELL-1 was associated with a significant increase in bone formation, as evidenced by increased BMD, bone volume, and mean cortical length. ${ }^{14,46}$ Furthermore, NELL-1 is associated with counteraction of the adverse effect of adipose-filled, poor-quality bone in bone morphogenetic protein
(BMP)-2-induced skeletal repair, possibly by directing BMP-2-treated cells away from adipogenesis and toward osteogenesis. $^{44}$

\section{Triglyceride-Related Metabolic Diseases}

Triglycerides (TGs) are circulating lipoproteins, the serum concentration of which reflects lipid status in clinical practice. ${ }^{47}$ Apart from serving as structural components,

Table 1 NELL1 Manifested in GWASs of Human Disorders

\begin{tabular}{|c|c|c|c|c|c|c|}
\hline Classification of disorders & Publication & $\begin{array}{l}\text { Sample } \\
\text { size }\end{array}$ & Ethnicity & $\begin{array}{l}\text { Evidence of } \\
\text { association }\end{array}$ & SNPS & Location on NELL1 \\
\hline \multicolumn{7}{|l|}{ Metabolic disease } \\
\hline Osteoporosis & Karasik et al $(2010)^{28}$ & - & - & Nominal & rs10766761 & Intron 12 \\
\hline ALL BMD loss & Inaba et al $(2018)^{29}$ & 393 & American & Suggestive & rs11025915 & Intron 12 \\
\hline TG metabolism & Del-Aguila et al $(2014)^{30}$ & 767 & American & Genome-wide & $\begin{array}{r}\text { rs12279250; } \\
\text { rs4319515 }\end{array}$ & Intron 16 ; intron 16 \\
\hline \multicolumn{7}{|c|}{$\begin{array}{l}\text { Neuropsychiatric and } \\
\text { neurodegenerative disorder }\end{array}$} \\
\hline Autism & Connolly et al (2013) & 2165 & American & Genome-wide & rs1429793 & Intron 5 \\
\hline Bipolar & Mathieu et al $(2015)^{33}$ & 291 & French & Suggestive & rs10766743 & Intron 5 \\
\hline MDD & Lin et al $(2018)^{34}$ & 455 & Taiwanese & Suggestive & rs2139423 & Intron 2 \\
\hline Chronic periodontitis & Sanders et al $(2017)^{36}$ & 10,935 & Hispanic & Suggestive & rs75715012 & Intergenic region \\
\hline Otitis media & van Ingen et al $(2016)^{27}$ & 8790 & American & Nominally & rs11026076 & Intron 15 \\
\hline \multicolumn{7}{|l|}{ Cancer } \\
\hline NSCLC & Wu et al $(2013)^{37}$ & 620 & American & Suggestive & rs10766739 & Intron 4 \\
\hline \multicolumn{7}{|l|}{ Other disorders } \\
\hline Cardiovascular mortality & Figarska $(2014)^{38}$ & 1546 & Caucasian & Suggestive & rs11026076 & Intron 15 \\
\hline QT prolongation & Seyerle et al $(2018)^{25}$ & 78,199 & European & Suggestive & rs12225793 & Intron 12 \\
\hline Ovarian aging & Voorhuis $(2013)^{39}$ & 791 & European & Suggestive & $\begin{array}{l}\text { rs7939346; } \\
\quad \text { rs10833509 }\end{array}$ & Intron 14 \\
\hline
\end{tabular}

*The specific loci of the 25 SNPs were not mentioned by the author.

-, not available; ALL, acute lymphoblastic leukemia; BMD, bone mineral density; GWAS, genome-wide association study; IBD, inflammatory bowel disease; MDD, major depressive disorder; NSCLC, non-small cell lung cancer; SNP, single-nucleotide polymorphism; TG, triglyceride. 
TGs are the energy reservoir that provide fuel for the body. ${ }^{47}$ In a genetic study, individuals with a weaker TG response to a treatment drug had a genetic profile different from those with a normal response. ${ }^{48}$

Del-Aguila et $\mathrm{al}^{30}$ conducted a GWAS of the TG response to hydrochlorothiazide, a drug widely prescribed for use in the treatment of patients with hypertension, which can cause hypertriglyceridemia. That study was performed in two independent populations composed of 425 European Americans and 342 African Americans. ${ }^{30}$ Two SNPs, rs12279250 and rs4319515, both in intron 16 of NELL1, showed genome-wide significance, while 77 SNPs in 27 genomic regions exhibited suggestive significance in the African-American population. The investigators conjectured that hydrochlorothiazide might regulate adipocyte differentiation through NELL-1, as NELL-1 was found to repress adipogenic differentiation. ${ }^{30}$

In another study, Rudkowska et $\mathrm{al}^{22}$ probed the effects of supplementation with long-chain $\Omega-3$ polyunsaturated fatty acids on the risk-related loci of inadequate plasma TG response. The study included 141 Canadians classified as responders or nonresponders. NELL1, among 13 loci, had suggestive significant association; rs752088, located in intron 2 of the NELL1 gene, was more frequent in nonresponders than in responders. ${ }^{22}$

Similarly, Aslibekyan et $\mathrm{a}^{31}$ performed a study of the changes in circulating adiponectin levels in response to fenofibrate therapy in 793 individuals from the United States. Several SNPs located on NELL1 were of suggestive significant association with baseline adiponectin level.

In an in vitro study, NELL1 was associated with reduced adipogenic differentiation in a human preadipocyte cell line, as evidenced by decreases in lipid droplet formation and expression of all of the adipogenic genes examined. ${ }^{16}$ In a study in a rodent model of femoral segmental defect, NELL-1 was reported to guide target cells away from adipogenesis. ${ }^{44}$ Considering the wellestablished genome-wide association of NELL1 with lipid metabolism, and the valid function testing of NELL1 in animal studies, the development NELL-1-related drugs to combat excessive fat production in diseases in humans is foreseeable.

\section{Neuropsychiatric and Neurodegenerative Disorders}

NELL-1 exhibits the highest expression in human and mouse brain tissues ${ }^{49}$ and plays an important role in skull morphogenesis. ${ }^{11}$ For these reasons, there is speculation that NELL-1 might play a role in neuropsychiatric and neurodegenerative disorders. Significantly, the discovery of Cntnap-4 as the NELL-1-specific receptor ${ }^{10}$ has prompted exploration of the potential regulatory role of NELL-1 in the nervous system in animal models. GWASs have revealed NELL1 to be one of the genes frequently associated with neural disorders. ${ }^{50-52}$

\section{Autism Spectrum Disorder}

Autism spectrum disorder (ASD) is a constellation of diseases characterized by repetitive, unusual sensorimotor behaviors and deficits in social communication. ${ }^{50}$ It has been reported that $74 \%$ to $93 \%$ of ASD risk is heritable. ${ }^{50}$ Evidence from a study in twins indicates that $16 \mathrm{p} 11.2$ deletions and CHD 8 are among the top genetic variants associated with ASD. ${ }^{53}$

Connolly et $\mathrm{al}^{32}$ performed a GWAS to detect susceptible genes associated with ASD. They selected endophenotypes from the commonly used behavioral assessments and included 2165 patients of European, Asian, or African descent. Among several of the candidate genes, NELL1 was found to be associated with endophenotypes of fainting, fits, or blackouts, and rs1429793, located in intron 5 of NELL1, showed genome-wide significance.

The investigators proposed that the association of NELL-1 with ASD might be a result of the comorbidity of ASD and other conditions, such as epilepsy. ${ }^{32}$ The NELL-1 binding partner, $\mathrm{PKC} \beta,{ }^{5}$ has been proposed as a target for anticonvulsant drugs. ${ }^{32}$ Notably, the NELL-1 receptor Cntnap-4 has been implicated in ASD. ${ }^{54}$ Cntnap-4 normally acts to attenuate dopamine release through a presynaptic mechanism. Cntnap4-knockout mice exhibit perseverative behaviors, such as over-grooming, which remains a common behavior abnormality in ASD mice. ${ }^{54}$ In addition, during human-gene analysis, patients diagnosed with ASD harbored exon deletion in the CNTNAP4 gene. ${ }^{54}$ Investigative work to understand the role of NELL-1 in ASD is ongoing.

\section{Bipolar Disorder}

Bipolar disorder, or manic depression, is characterized by episodic and recurrent mood transition from extreme elation to severe depression. ${ }^{51}$ Inheritable factors play an important role in the pathogenesis of the disease, and family history is a clinical predictor. ${ }^{55}$ The diagnosis of bipolar disorder is primarily based on clinical features. ${ }^{51}$ The inclusion of a quantitative trait, emotional reactivity (the threshold and magnitude to which one responds in emotion-eliciting situations), has largely contributed to the identification of susceptible genes in bipolar disorder.

Mathieu et $\mathrm{al}^{33}$ performed a study of the genetic background of 281 patients from France who met the criteria for bipolar disorder. They selected emotional reactivity to quantify the severity of bipolar disorder. On GWAS, rs 10766743, located in NELL1 intron 5, remained the single SNP with suggestive significance after adjustment for multiple comparisons using the Bonferroni correction.

Similar to that in other diseases of the nervous system, the functional role of NELL-1 in bipolar disorder has not yet been tested. More functional experiments are required to verify the role of NELL-1 in bipolar disorder.

\section{Major Depressive Disorder}

Major depressive disorder is a group of psychosocialdysfunction diseases manifested by a combination of 
emotional, neurovegetative, and neurocognitive symptoms. ${ }^{56}$ In genetic studies, major depressive disorder has been reported as moderately inheritable through multiple genes. $^{57}$

Lin et $\mathrm{al}^{34}$ implemented a study in 455 Taiwanese patients diagnosed with major depressive disorder to hone in a predictive model for an antidepressant response. The investigators first performed a GWAS to select the candidate gene loci. They then built a predictive model with a combination of patients' clinical and genetic biomarkers. In the association study, NELLI was among the top 10 genes predictive of treatment response. The SNP located in intron 2 of NELL1, rs2139423, was detected to be of suggestive significance.

As current studies have not implicated the functional role of NELL-1 in mediating psychiatric disorders, the antidepressant role of NELL-1 requires further elucidation.

\section{Multiple Sclerosis}

Multiple sclerosis is a degenerative disease of the central nervous system caused by neuroinflammation. The clinical manifestation of multiple sclerosis is dependent on the location of the affected central nervous system region and the extent of the inflammatory process. ${ }^{52,58}$ Genetic factors play a prominent role in the development of the disease. ${ }^{52}$ An association between a multiple sclerosis subtype and human leukocyte antigen DR isotype 15 and 16 has long been known and consistently replicated. ${ }^{52}$

In a study of 608 Caucasians screened for the candidate genes that contribute to the outcomes of patients with multiple-sclerosis relapse, NELL1 was found to be of suggestive significance. The SNP rs7130553, located in intron 15 , was suspected. ${ }^{35}$ The fact that NELL-1 is highly expressed in brain tissue may have accounted for this observation. Studies of the function of NELL-1 in multiple sclerosis have not yet been performed.

\section{Inflammatory Diseases}

The first association of NELL1 with diseases in GWASs appeared in a 2007 study of the susceptibility of the gene in inflammatory bowel disease (IBD). ${ }^{23}$ Indeed, NELL1 has been linked to other inflammatory diseases, including periodontitis and otitis media.

\section{Inflammatory Bowel Disease}

IBD is a group of chronic inflammatory disorders of the gastrointestinal tract, featured by two subtypes, Crohn disease, and ulcerative colitis. ${ }^{59}$ The onset and progression of IBD are attributed to the dysregulated immune response of the resident microbial communities in a genetically susceptible host. Genetic studies have revealed $>240$ loci that confer a risk for IBD, but the contribution of these genetic variants to the disease remains largely unknown. ${ }^{59}$ Among these genes, NELL1 has been shown by GWASs to be susceptible. ${ }^{23,24}$

Franke et $\mathrm{al}^{23}$ performed a multistage genome-wide scan in different panels. They first conducted the screening in a German panel of 393 cases of Crohn disease and 399 controls and identified the 200 most significant SNPs. In the subsequent replication study in an independent German panel, rs1793004, located in intron 1 of NELL1, showed a consistent association of suggestive significance with Crohn disease. The German panel comprised 942 patients, 1082 controls, and 375 trios, and rs1793004 was also associated with the ulcerative colitis case-control panel, highlighting NELL1 as a ubiquitous IBD-susceptibility gene. In the replication study, two additional SNPs, rs8176785 and rs8176786, located on exons 3 and 10 respectively, showed an association of suggestive significance with Crohn disease. The SNPs in the two exons both were missense mutations. Since the initial identification of NELL1 as a susceptible gene in IBD, several replication studies from other research centers have ensued. Studies in a Dutch-Belgian cohort and in a Canadian population failed to show statistical association with NELL1. ${ }^{24,60}$ The fact that the German study included stringent criteria for Crohn disease, in which only patients with the severe phenotype ${ }^{23}$ were included in the analysis, might account for the discrepancy among the studies.

Apart from association studies, histologic and molecular studies in IBD patients have indicated interesting results. Substantial NELL1 transcript levels were detected in the colon and small intestine. However, no significant differences between normal and affected tissue were revealed by quantitative PCR. Localization of NELL-1 in colonic mucosa by immunohistochemistry analysis showed a confined expression in inflammatory cells in the lamina propria. $^{23}$

Although the association between IBD and NELL1 was susceptible to population stratification, interestingly, osteopenia and osteoporosis were among the top comorbidities in IBD patients. ${ }^{61,62}$ Sophisticated diagnostic modalities also demonstrated that young IBD patients experienced more bone fragility. ${ }^{63}$ It was suggested that BMD and bone microstructure could serve as early diagnostic criteria to better identify IBD patients. ${ }^{63}$ Thus, it is reasonable to infer that NELL-1 may be associated with comorbidities of IBD rather than susceptibility to IBD per se. ${ }^{23}$ Moreover, so far, two SNPs, rs8176785 and rs8176786, are the only NELL1 SNPs in the coding exons identified and associated in GWAS reports across many disorders in humans. In this case, the actual roles of the identified SNPs in the development of IBD could be pursued by the construction of the corresponding point-mutation vectors or by the use of the CRISPR/CAS9 gene-editing technique in both in vitro and in vivo models. ${ }^{64}$ The verification and validation of the functions of NELL1 SNPs may be assayed as suggested elsewhere ${ }^{65-69}$ (Figure 2). 


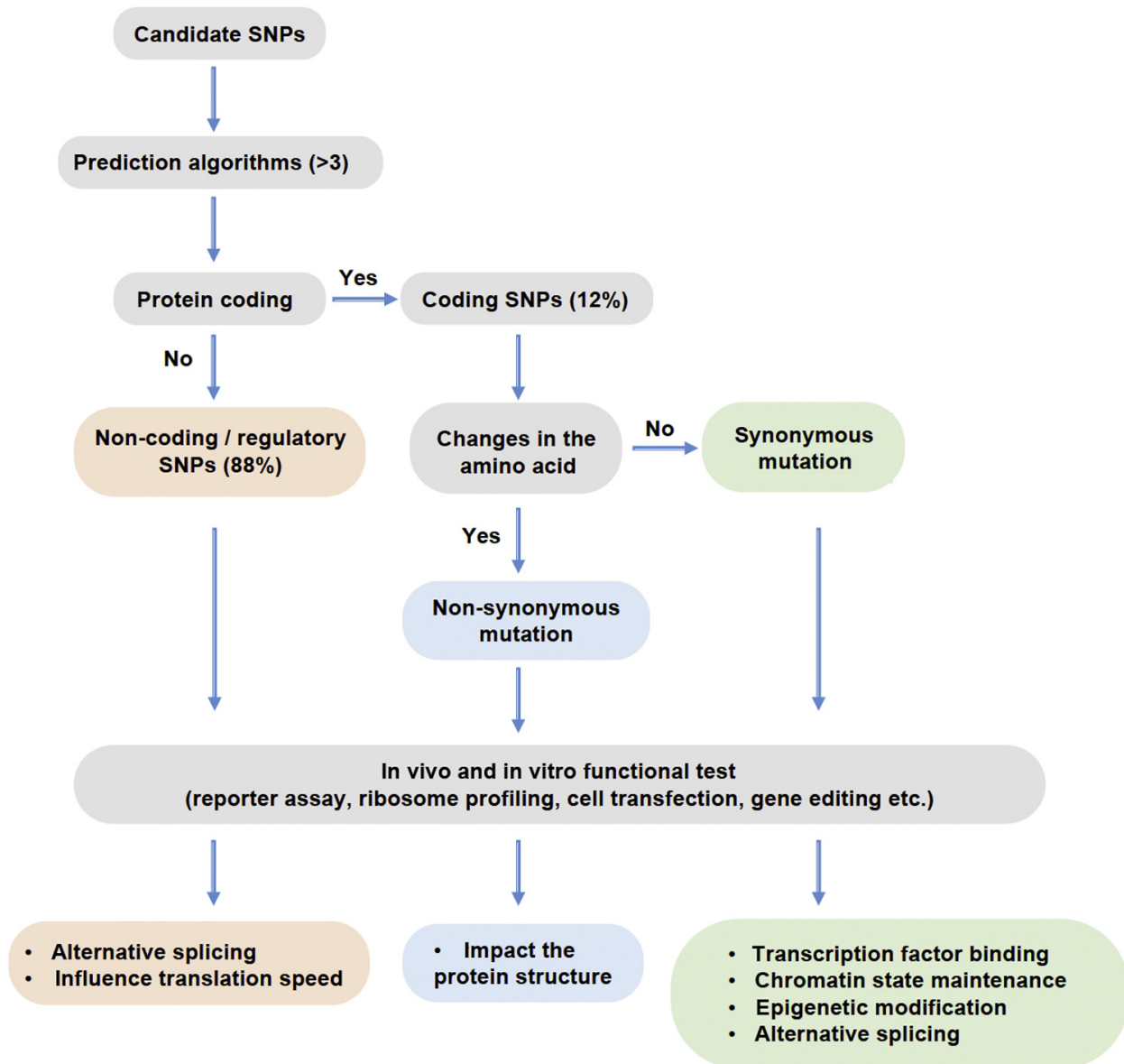

Figure 2 Functional validation of candidate SNPs. For candidate SNPs of statistical significance revealed by GWASs, further bioinformatics analysis is applied to categorize them as coding or noncoding. Usually, a combination of multiple servers (more than three) with complementary algorithms was used to minimize errors. ${ }^{66}$ In the GWASs in the literature, up to $88 \%$ of the SNPs screened are noncoding. ${ }^{68}$ Coding SNPs were subclassified as nonsynonymous mutations, in which the amino acid and consequently the encoded protein is changed, and synonymous mutations. ${ }^{69}$ While nonsynonymous SNPs could have a direct impact on the protein structure, synonymous SNPs could lead to alternative splicing, or limit the speed of the translation. ${ }^{67}$ Noncoding SNPs can also be called regulatory SNPs, which can be located in the promoter, enhancer, $5^{\prime}$-untranslated region (UTR), $3^{\prime}$-UTR, or intronic region. First, GWAS, linkage analysis, and quantitative trait locus mapping are frequently used to detect causal regulatory SNPs. ${ }^{68}$ Then, functional testing can be applied to determine the role of targeted SNPs to be transcription-factor binding, chromatin state maintenance, epigenetic modification, ${ }^{68}$ or alternative splicing. ${ }^{65}$ The general framework of functional validation of noncoding SNPs is suggested elsewhere. ${ }^{68}$

\section{Chronic Periodontitis}

Chronic periodontitis is a progressive inflammatory disease characterized by gradual detachment of the periodontal tissue from the tooth and a loss of alveolar bone. ${ }^{70,71}$ The cause of chronic periodontitis involves a dynamic interaction between the periodontal microbiota and the hostdefense system, which is under strong genetic control. ${ }^{70}$ Studies in twins have verified the heritability of chronic periodontitis, and a handful of GWASs have begun to unravel the genetic susceptibility of the disease..$^{71-73}$ To date, no gene has been found to be of genome-wide significance, although several bear suggestive significance..$^{72,73}$

Five GWASs of chronic periodontitis were conducted in Caucasian and Asian populations. ${ }^{26,72-75}$ However, none of them found a gene locus of genome-wide significant association. $^{36,71}$ Then Sanders et $\mathrm{al}^{36}$ performed a GWAS in 10,395 Hispanic/Latino participants, followed by a replication study in 4402 European Americans and 908 African
Americans. They selected interproximal clinical attachment levels as the measurement of chronic periodontitis and reported one gene locus of genome-wide significance and four others of suggestive significance. The NELL1 gene, with its nearby SNP rs75715012, showed suggestive significance.

Apart from association studies, in vitro and in vivo animal studies have also revealed the functional role of NELL-1 in tooth and periodontal tissues. ${ }^{52}$ NELL-1 may promote osteogenic differentiation in human periodontal ligament stem cells. ${ }^{76}$ Moreover, NELL-1 demonstrated osteoinductive capacity to promote bone formation in alveolar bone areas within rhesus-monkey and rat models. ${ }^{77,78}$

\section{Acute Otitis Media}

Otitis media remains a highly prevalent childhood disease worldwide, of which acute otitis media (AOM) accounts for the largest percentage. ${ }^{27,79} \mathrm{AOM}$ is characterized by the presence of fluid in the middle-ear cavity, frequently 


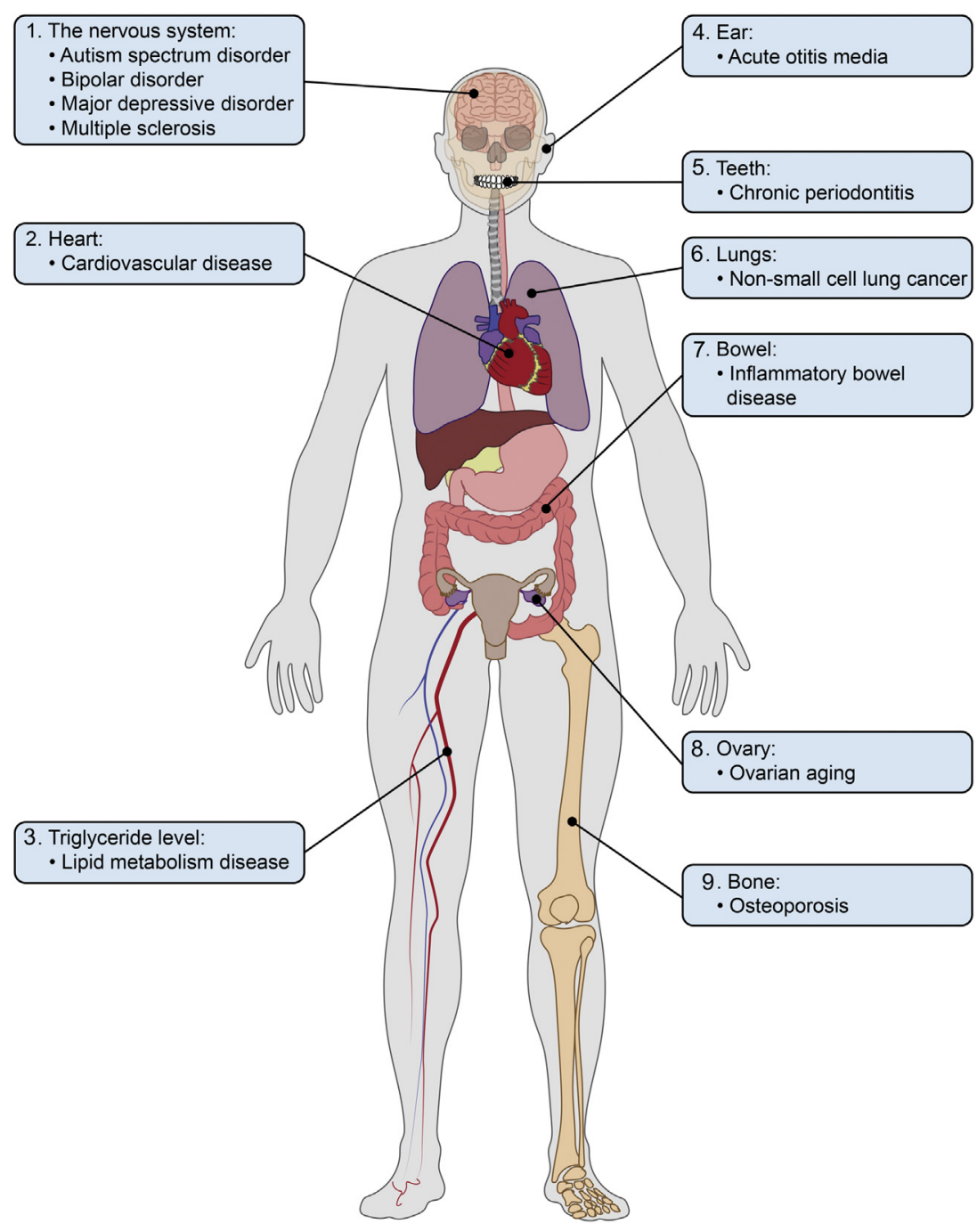

Figure 3 Human disorders with NELL1 manifestation in GWASs.

accompanied by earache, fever, and upper respiratory tract infection. ${ }^{80}$ The cause of AOM involves multiple aspects of the pathogen, host, and genetic factors. ${ }^{80,81}$ The heritability of AOM is well established, and FNDC1 has been identified as a disease-contributing gene. ${ }^{27}$ Furthermore, GWASs have unraveled several other susceptible gene loci in AOM. ${ }^{27,79,82}$

Van Ingen et $\mathrm{al}^{27}$ performed a GWAS in AOM in an American population with 825 cases and 7936 controls. They discovered 1 gene of genome-wide significance and 8 genes of suggestive significance. In addition, they found that 45 of 82 genes demonstrated nominally significant association. The NELL1 gene, with its SNP rs11026076 in intron 15 , fell into the latter category.

Evidence of the association between NELL-1 and AOM is still at its preliminary stage. Further studies are needed to verify this association and to illustrate the possible functional role of NELL-1 in AOM.

\section{Non-Small Cell Lung Cancer}

Non-small cell lung cancer (NSCLC) is the most common type of lung cancer and accounts for nearly $80 \%$ of cases. ${ }^{83}$
Although smoking is an important risk factor for NSCLC, a notable amount of NSCLC patients have never smoked. ${ }^{37}$ These observations led to the discovery that nonsmokers with NSCLC bear a distinct genetic profile in comparison to smokers with NSCLC. ${ }^{84}$ The $A L K$ gene ranked top among the NSCLC oncogenes. ${ }^{83}$

In order to investigate the genetic variants of NSCLC in nonsmokers, $\mathrm{Wu}$ et $\mathrm{al}^{37}$ conducted a GWAS. The study included as a screening panel 620 American patients and normal controls from two medical centers. The top 25 gene candidates generated from this study were replicated in 1256 Taiwanese patients. Only two genes were still significant after the replication analysis. The SNP in intron 4 of NELL1, rs10766739, ranked among the top candidate loci in the screening panel $\left(P=3.66 \times 10^{-7}\right)$ and was of borderline significance $(P=0.051)$ in the replication panel. Therefore, NELL1 emerged as a candidate tumor-suppressor gene. This is supported by its potentially protective role in other types of tumors, such as esophageal adenocarcinoma and colon cancer, ${ }^{18,19}$ although more validation studies are needed.

In parallel to GWAS, studies of the function of NELL-1 in tumorigenesis have yielded corroborating results. NELL1 
promoter region is hypermethylated, a hallmark of gene inactivation, in colon cancer tissue compared to normal colon tissue. ${ }^{19}$ Similarly, in esophageal adenocarcinoma, NELL1 exhibits a loss of heterozygosity and promoter hypermethylation, two mechanisms of gene inactivation. ${ }^{18}$ The application of demethylation agents could decrease promoter methylation and up-regulate NELL-1 expression in both colon cancer and esophageal adenocarcinoma cell lines. ${ }^{18,19}$ Furthermore, in a recent study in lung cancer stem-like cells, ${ }^{85}$ overexpression of NELL-1 in a 95-D human cell line, a highly invasive and metastatic lung carcinoma cell line, was associated with cell differentiation and thus a reduction in metastasis. Together, these results support the promising tumor-suppressing role of NELL-1.

\section{Other Human Disorders}

In GWASs, NELL-1 has also been implicated in other human disorders that are not categorized readily, such as cardiovascular diseases and ovarian aging. ${ }^{38,39}$ The SNP rs11026076, located in intron 15 of NELL1 gene, is positively associated with cardiovascular mortality with suggestive significance. ${ }^{38}$ In a human functional study by Chen et al, ${ }^{86}$ NELL-1 protected the mitral valve from inflammatory injury. Another GWAS explored thiazide diuretics-induced QT-interval prolongation. A total of 78,199 Europeans, African Americans, and Hispanics were enrolled in that study, in which rs12225793 in intron 12 of NELL1 was of suggestive association with QT prolongation. ${ }^{25}$ Two SNPs, rs7939346 and rs10833509, both in intron 14 of $N E L L 1$, were suggestively significantly associated with ovarian aging. ${ }^{39}$ However, currently, no studies of the function of NELL-1 in ovarian aging are available.

\section{Conclusions and Future Perspectives}

In the relevant GWASs of NELL1, a spectrum of diseases, including bone-related metabolic diseases, lipid-metabolic diseases, inflammatory conditions, neuropsychiatric diseases, neurodegenerative disorders, and cancers have been implicated (Figure 3). Taking into account the high replicability of GWASs and verifications of the relevant function studies, NELL1 gene polymorphisms are likely to have significant associations with a wide variety of disorders in humans.

On the other hand, it is also apparent that these GWASs have some limitations. First, the heritability explained by GWASs is relatively low, and the biological significance and GWAS-based association of a certain gene could be disproportionate. So, the contribution of NELL-1 to the onset and progression of these diseases or to the responsiveness to specific treatments is uncertain. Second, the GWAS-based data on NELL1 presented in this review are all directly drawn from primary individual studies, which do not include preliminary results from indirect meta-analyses. ${ }^{87-89}$ Third, GWAS-based signals could be spurious because of cryptic population stratification. Thus, a sober perception of the exact role of NELL-1 in all of the aforementioned diseases should be further interrogated in post-GWAS function studies.

While GWASs offer new perspectives on the genetic architecture of diseases, the results should be interpreted conservatively. The practical realization of whole-genome sequencing will tremendously improve studies on SNPs in the noncoding regions of NELL1. With a better understanding of multiple potential roles of the NELLI gene in disorders in humans, this review highlights the future perspectives for research on NELL-1, shifting from investigations on associations to those on function and causation.

\section{Acknowledgments}

We thank Drs. Bihe Zhang and Dan Pan for their feedback on the figures. We also thank Joshua Yang and Yasamin Mohazeb for English-language editing.

\section{Author Contributions}

X.C. contributed to the investigation and drafted the manuscript; J.S. drafted the manuscript; Z.J. provided genetic interpretation and drafted the manuscript; P.H., C.S., and K.T. supervised the work; A.W.J. and B.S. supervised the work and critically revised the manuscript; X.Z. conceptualized and supervised the work and critically revised the manuscript; X.C., C.S., T.K., B.S., and X.Z. acquired funding. All of the authors approved the manuscript and are accountable for all aspects of the work.

\section{References}

1. Marigorta UM, Rodríguez JA, Gibson G, Navarro A: Replicability and prediction: lessons and challenges from GWAS. Trends Genet 2018, 34:504-517

2. Jhamb D, Magid-Slav M, Hurle MR, Agarwal P: Pathway analysis of GWAS loci identifies novel drug targets and repurposing opportunities. Drug Discov Today 2019, 24:1232-1236

3. Tam V, Patel N, Turcotte M, Bossé Y, Paré G, Meyre D: Benefits and limitations of genome-wide association studies. Nat Rev Genet 2019 , 20:467-484

4. Zhang X, Zara J, Siu RK, Ting K, Soo C: The role of NELL-1, a growth factor associated with craniosynostosis, in promoting bone regeneration. J Dent Res 2010, 89:865-878

5. Li C, Zhang X, Zheng Z, Nguyen A, Ting K, Soo C: Nell-1 is a key functional modulator in osteochondrogenesis and beyond. J Dent Res 2019, 98:1458-1468

6. Watanabe TK, Katagiri T, Suzuki M, Shimizu F, Fujiwara T, Kanemoto N, Nakamura Y, Hirai Y, Maekawa H, Takahashi EI: Cloning and characterization of two novel human cDNAs (NELL1 and NELL2) encoding proteins with six EGF-like repeats. Genomics 1996, 38:273-276

7. Ting K, Vastardis H, Mulliken JB, Soo C, Tieu A, Do H, Kwong E, Bertolami CN, Kawamoto H, Kuroda S, Longaker MT: Human NELL-1 expressed in unilateral coronal synostosis. J Bone Miner Res $1999,14: 80-89$ 
8. Yamamoto N, Kashiwagi M, Ishihara M, Kojima T, Niimi T: Robo2 contains a cryptic binding site for neural EGFL-like (NELL) protein 1/2. J Biol Chem 2019, 294:4693-4703

9. Nakamura Y, Hasebe A, Takahashi K, Iijima M, Yoshimoto N, Ting K, Niimi T: Oligomerization-induced conformational change in the c-terminal region of Nel-like molecule 1 (NELL1) protein is necessary for the efficient mediation of murine MC3T3-E1 cell adhesion and spreading. J Biol Chem 2014, 289:9781-9794

10. Li C, Zheng Z, Ha P, Chen X, Jiang W, Sun S, Chen F, Asatrian G, Berthiaume EA, Kim JK, Chen EC, Pang S, Zhang X, Ting K, Soo C: Neurexin superfamily cell membrane receptor contactinassociated protein like-4 (Cntnap4) is involved in neural EGFL-like 1 (Nell-1)-responsive osteogenesis. J Bone Miner Res 2018, 33: $1813-1825$

11. Zhang X, Kuroda S, Carpenter D, Nishimura I, Soo C, Moats R, Iida K, Wisner E, Hu F, Miao S, Beanes S, Dang C, Vastardis H, Longaker M, Tanizawa K, Kanayama N, Saito N, Ting K: Craniosynostosis in transgenic mice overexpressing Nell-1. J Clin Invest 2002, 110:861-870

12. Li C, Zheng Z, Zhang X, Asatrian G, Chen E, Song R, Culiat C, Ting K, Soo C: Nfatc1 is a functional transcriptional factor mediating nell-1-induced Runx3 upregulation in chondrocytes. Int J Mol Sci 2018, 19:168-183

13. Qi H, Kim JK, Ha P, Chen X, Chen E, Chen Y, Li J, Pan HC, Yu M, Mohazeb Y, Azer S, Baik L, Kwak JH, Ting K, Zhang X, $\mathrm{Hu}$ M, Soo C: Inactivation of Nell-1 in chondrocytes significantly impedes appendicular skeletogenesis. J Bone Miner Res 2019, 34: $533-546$

14. James AW, Shen J, Zhang X, Asatrian G, Goyal R, Kwak JH, Jiang L, Bengs B, Culiat CT, Turner AS, Seim HB, Wu BM, Lyons K, Adams JS, Ting K, Soo C: NELL-1 in the treatment of osteoporotic bone loss. Nat Commun 2015, 6:7362-7375

15. Pakvasa M, Alverdy A, Mostafa S, Wang E, Fu L, Li A, Oliveira L, Athiviraham A, Lee MJ, Wolf JM, He TC, Ameer GA, Reid RR: Neural EGF-like protein 1 (NELL-1): signaling crosstalk in mesenchymal stem cells and applications in regenerative medicine. Genes Dis 2017, 4:127-137

16. James AW, Pan A, Chiang M, Zara JN, Zhang X, Ting K, Soo C: A new function of Nell-1 protein in repressing adipogenic differentiation. Biochem Biophys Res Commun 2011, 23:1-7

17. Li C, Zheng Z, Ha P, Jiang W, Berthiaume EA, Lee S, Mills Z, Pan H, Chen EC, Jiang J, Culiat CT, Zhang X, Ting K, Soo C: Neural EGFL like 1 as a potential pro-chondrogenic, anti-inflammatory dualfunctional disease-modifying osteoarthritis drug. Biomaterials 2020, 226:119541

18. Jin Z, Mori Y, Yang J, Sato F, Ito T, Cheng Y, Paun B, Hamilton JP, Kan T, Olaru A, David S, Agarwal R, Abraham JM, Beer D, Montgomery E, Meltzer SJ: Hypermethylation of the nel-like 1 gene is a common and early event and is associated with poor prognosis in early-stage esophageal adenocarcinoma. Oncogene 2007, 26: $6332-6340$

19. Mori Y, Cai K, Cheng Y, Wang S, Paun B, Hamilton JP, Jin Z, Sato F, Berki AT, Kan T, Ito T, Mantzur C, Abraham JM, Meltzer SJ: A genome-wide search identifies epigenetic silencing of somatostatin, tachykinin-1, and 5 other genes in colon cancer. Gastroenterology 2006, 131:797-808

20. Hanset N, Aydin S, Demoulin N, Cosyns J, Castanares-Zapatero D, Crott R, Cambier J, Pochet J, Gillerot G, Reginster F: Podocyte antigen staining to identify distinct phenotypes and outcomes in membranous nephropathy: a retrospective multicenter cohort study. Am J Kidney Dis 2020, 76:624-635

21. Sethi S, Debiec H, Madden B, Charlesworth MC, Morelle J, Gross L, Ravindran A, Buob D, Jadoul M, Fervenza FC: Neural epidermal growth factor-like 1 protein (NELL-1) associated membranous nephropathy. Kidney Int 2020, 97:163-174

22. Rudkowska I, Guénard F, Julien P, Couture P, Lemieux S, Barbier O, Calder PC, Minihane AM, Vohl MC: Genome-wide association study of the plasma triglyceride response to an $n-3$ polyunsaturated fatty acid supplementation. J Lipid Res 2014, 55:1245-1253

23. Franke A, Hampe J, Rosenstiel P, Becker C, Wagner F, Häsler R, Little RD, Huse $\mathrm{K}$, Ruether A, Balschun $\mathrm{T}$, Wittig $\mathrm{M}$, ElSharawy A, Mayr G, Albrecht M, Prescott NJ, Onnie CM, Fournier H, Keith T, Radelof U, Platzer M, Mathew CG, Stoll M, Krawczak M, Nürnberg P, Schreiber S: Systematic association mapping identifies NELL1 as a novel IBD disease gene. PLoS One 2007, 2:e691

24. Amre DK, MacK DR, Israel D, Krupoves A, Costea I, Lambrette P, Grimard G, Dong J, Levy E: NELL1, NCF4, and FAM92B genes are not major susceptibility genes for Crohn's disease in Canadian children and young adults. Inflamm Bowel Dis 2012, 18:529-535

25. Seyerle AA, Sitlani CM, Noordam R, Gogarten SM, Li J, Li X, et al: Pharmacogenomics study of thiazide diuretics and QT interval in multi-ethnic populations: the cohorts for heart and aging research in genomic epidemiology. Pharmacogenomics J 2018, 18: 215-226

26. Shaffer JR, Polk DE, Wang X, Feingold E, Weeks DE, Lee MK, Cuenco KT, Weyant RJ, Crout RJ, McNeil DW, Marazita ML: Genomewide association study of periodontal health measured by probing depth in adults ages 18-49 years. G3 (Bethesda) 2014, 4:307-314

27. Van Ingen G, Li J, Goedegebure A, Pandey R, Rose Li Y, March ME, Jaddoe VWV, Bakay M, Mentch FD, Thomas K, Wei Z, Chang X, Hain HS, Uitterlinden AG, Moll HA, Van Duijn CM, Rivadeneira F, Raat H, De Jong RJB, Sleiman PM, Van Der Schroeff MP, Hakonarson H: Genome-wide association study for acute otitis media in children identifies FNDC1 as disease contributing gene. Nat Commun 2016, 7:1-7

28. Karasik D, Hsu YH, Zhou Y, Cupples LA, Kiel DP, Demissie S: Genome-wide pleiotropy of osteoporosis-related phenotypes: the Framingham study. J Bone Miner Res 2010, 25:1555-1563

29. Inaba H, Cao X, Han AQ, Panetta JC, Ness KK, Metzger ML, Rubnitz JE, Ribeiro RC, Sandlund JT, Jeha S, Cheng C, Pui CH, Relling MV, Kaste SC: Bone mineral density in children with acute lymphoblastic leukemia. Cancer 2018, 124:1025-1035

30. Del-Aguila JL, Beitelshees AL, Cooper-Dehoff RM, Chapman AB, Gums JG, Bailey K, Gong Y, Turner ST, Johnson JA, Boerwinkle E: Genome-wide association analyses suggest NELL1 influences adverse metabolic response to HCTZ in African Americans. Pharmacogenomics J 2014, 14:35-40

31. Aslibekyan S, An P, Frazier-Wood AC, Kabagambe EK, Irvin MR, Straka RJ, Tiwari HK, Tsai MY, Hopkins PN, Borecki IB, Ordovas JM, Arnett DK: Preliminary evidence of genetic determinants of adiponectin response to fenofibrate in the Genetics of Lipid Lowering Drugs and Diet Network. Nutr Metab Cardiovasc Dis 2013, 23:987-994

32. Connolly JJ, Glessner JT, Hakonarson H: A genome-wide association study of autism incorporating autism diagnostic interview-revised, autism diagnostic observation schedule, and social responsiveness scale. Child Dev 2013, 84:17-33

33. Mathieu F, Etain B, Dizier MH, Lajnef M, Lathrop M, Cabon C, Leboyer M, Henry C, Bellivier F: Genetics of emotional reactivity in bipolar disorders. J Affect Disord 2015, 188:101-106

34. Lin E, Kuo PH, Liu YL, Yu YWY, Yang AC, Tsai SJ: A deep learning approach for predicting antidepressant response in major depression using clinical and genetic biomarkers. Front Psychiatry 2018, 6:290-299

35. Tiwari H, Patki A, Cofield SS, Gustafson T, Duggan D, Jacobson S, Wolinsky JS, Lublin FD, Cutter GR; The CombiRx Investigator Group: GWAS on relapse outcomes in CombiRx trial Poster presented at: 31st Congress of European Committee for Treatment and Research in Multiple Sclerosis (ECTRIMS), Barcelona, Spain, October 7-10; 2015

36. Sanders AE, Sofer T, Wong Q, Kerr KF, Agler C, Shaffer JR, Beck JD, Offenbacher S, Salazar CR, North KE, Marazita ML, Laurie CC, Singer RH, Cai J, Finlayson TL, Divaris K: Chronic 
periodontitis genome-wide association study in the Hispanic community health study/study of Latinos. J Dent Res 2017, 96:64-72

37. Wu X, Wang L, Ye Y, Aakre JA, Pu X, Chang GC, Yang PC, Roth JA, Marks RS, Lippman SM, Chang JY, Lu C, Deschamps C, Su WC, Wang WC, Huang MS, Chang DW, Li Y, Pankratz VS, Minna JD, Hong WK, Hildebrandt MAT, Hsiung CA, Yang P: Genome-wide association study of genetic predictors of overall survival for non-small cell lung cancer in never smokers. Cancer Res 2013, 73:4028-4038

38. Figarska S. Genetics of healthy ageing (dissertation). [Groningen, the Netherlands]: University of Groningen.

39. Voorhuis M. Genetics of ovarian ageing: genetic association studies on natural. menopause and primary ovarian insufficiency (master's thesis). [Utrecht, the Netherlands]: Utrecht University.

40. Rivadeneira F, Styrkársdottir U, Estrada K, Halldórsson BV, Hsu Y$\mathrm{H}$, Richards JB, Zillikens MC, Kavvoura FK, Amin N, Aulchenko YS, Cupples LA, Deloukas P, Demissie S, Grundberg E, Hofman A, Kong A, Karasik D, van Meurs JB, Oostra B, Pastinen T, Pols HAP, Sigurdsson G, Soranzo N, Thorleifsson G, Thorsteinsdottir U, Williams FMK, Wilson SG, Zhou Y, Ralston SH, van Duijn CM, Spector T, Kiel DP, Stefansson K, Ioannidis JPA, Uitterlinden AG: Twenty bone-mineral-density loci identified by large-scale meta-analysis of genome-wide association studies. Nat Genet 2009, 41:1199-1206

41. Kiel DP, Demissie S, Dupuis J, Lunetta KL, Murabito JM, Karasik D: Genome-wide association with bone mass and geometry in the Framingham heart study. BMC Med Genet 2007, 8(Suppl 1):S14

42. Styrkarsdottir U, Halldorsson BV, Gretarsdottir S, Gudbjartsson DF, Walters GB, Ingvarsson T, Jonsdottir T, Saemundsdottir J, Center JR, Nguyen TV, Bagger Y, Gulcher JR, Eisman JA, Christiansen C, Sigurdsson G, Kong A, Thorsteinsdottir U, Stefansson K: Multiple genetic loci for bone mineral density and fractures. N Engl J Med 2008, 358:2355-2365

43. Cox CL, Zhu L, Kaste SC, Srivastava K, Barnes L, Nathan PC, Wells RJ, Ness KK: Modifying bone mineral density, physical function, and quality of life in children with acute lymphoblastic leukemia. Pediatr Blood Cancer 2018, 65:1-8

44. Shen J, James AW, Zhang X, Pang S, Zara JN, Asatrian G, Chiang M, Lee M, Khadarian K, Nguyen A, Lee KS, Siu RK, Tetradis S, Ting K, Soo C: Novel Wnt regulator NEL-like molecule-1 antagonizes adipogenesis and augments osteogenesis induced by bone morphogenetic protein 2. Am J Pathol 2016, 186: 419-434

45. Lee S, Zhang X, Shen J, James AW, Chung CG, Hardy R, Li C, Girgius C, Zhang Y, Stoker D, Wang H, Wu BM, Peault B, Ting K, Soo C: Brief report:human perivascular stem cells and Nel-like protein-1 synergistically enhance spinal fusion in osteoporotic rats. Stem Cells 2015, 33:3158-3163

46. James AW, Chiang M, Asatrian G, Shen J, Goyal R, Chung CG, Chang L, Shrestha S, Turner AS, Seim HB 3rd, Zhang X, Wu BM, Ting K, Soo C: Vertebral implantation of NELL-1 enhances bone formation in an osteoporotic sheep model. Tissue Eng Part A 2016, 22:840-849

47. Sandesara PB, Virani SS, Fazio S, Shapiro MD: The forgotten lipids: triglycerides, remnant cholesterol, and atherosclerotic cardiovascular disease risk. Endocr Rev 2019, 40:537-557

48. Kraja AT, Borecki IB, Tsai MY, Ordovas JM, Hopkins PN, Lai CQ, Frazier-Wood AC, Straka RJ, Hixson JE, Province MA, Arnett DK: Genetic analysis of 16 NMR-lipoprotein fractions in humans, the GOLDN study. Lipids 2013, 48:155-165

49. Kuroda S, Tanizawa K: Involvement of epidermal growth factor-like domain of NELL proteins in the novel protein-protein interaction with protein kinase C. Biochem Biophys Res Commun 1999, 265: $752-757$

50. Lord C, Elsabbagh M, Baird G, Veenstra-Vanderweele J: Seminar Autism spectrum disorder. Lancet 2018, 392:508-520

51. Craddock N, Sklar P: Bipolar disorder 1 - genetics of bipolar disorder. Lancet 2013, 381:1654-1662
52. Thompson AJ, Baranzini SE, Geurts J, Hemmer B, Ciccarelli O: Seminar multiple sclerosis. Lancet 2018, 391:1622-1636

53. Bailey A, Le Couteur A, Gottesman I, Bolton P, Simonoff E, Yuzda E, Rutter M: Autism as a strongly genetic disorder: evidence from a British twin study. Psychol Med 1995, 25:63-77

54. Karayannis T, Au E, Patel JC, Kruglikov I, Markx S, Delorme R, Héron D, Salomon D, Glessner J, Restituito S, Gordon A, RodriguezMurillo L, Roy NC, Gogos JA, Rudy B, Rice ME, Karayiorgou M, Hakonarson H, Keren B, Huguet G, Bourgeron T, Hoeffer C, Tsien RW, Peles E, Fishell G: Cntnap4 differentially contributes to GABAergic and dopaminergic synaptic transmission. Nature 2014, 511:236-240

55. McGuffin P, Rijsdijk F, Andrew M, Sham P, Katz R, Cardno A: The heritability of bipolar affective disorder and the genetic relationship to unipolar depression. Arch Gen Psychiatry 2003, 60:497-502

56. Wray NR, Ripke S, Mattheisen M, Trzaskowski M, Byrne EM, Abdellaoui A, et al: Genome-wide association analyses identify 44 risk variants and refine the genetic architecture of major depression. Nat Genet 2018, 50:668-681

57. Howard DM, Adams MJ, Shirali M, Clarke TK, Marioni RE, Davies G, Coleman JRI, Alloza C, Shen X, Barbu MC, Wigmore EM, Gibson J, Hagenaars SP, Lewis CM, Ward J, Smith DJ, Sullivan PF, Haley CS, Breen G, Deary IJ, McIntosh AM: Genome-wide association study of depression phenotypes in UK Biobank identifies variants in excitatory synaptic pathways. Nat Commun 2018, 9:1470-1479

58. Grossman I, Knappertz V, Laifenfeld D, Ross C, Zeskind B, Kolitz S, Ladkani D, Hayardeny L, Loupe P, Laufer R, Hayden M: Pharmacogenomics strategies to optimize treatments for multiple sclerosis: insights from clinical research. Prog Neurobiol 2017, 152:114-130

59. Furey TS, Sethupathy P, Sheikh SZ: Redefining the IBDs using genome-scale molecular phenotyping. Nat Rev Gastroenterol Hepatol 2019, 16:296-311

60. Weersma RK, Stokkers PCF, Cleynen I, Wolfkamp SCS, Henckaerts L, Schreiber S, Dijkstra G, Franke A, Nolte IM, Rutgeerts P, Wijmenga C, Vermeire S: Confirmation of multiple Crohn's disease susceptibility loci in a large Dutch-Belgian cohort. Am J Gastroenterol 2009, 104:630-638

61. Roux C, Abitbol V, Chaussade S, Kolta S, Guillemant S, Dougados M, Amor B, Couturier D: Bone loss in patients with inflammatory bowel disease: a prospective study. Osteoporos Int 1995, 5:156-160

62. Abitbol V, Roux C, Chaussade S, Guillemant S, Kolta S, Dougados M, Couturier D, Amor B: Metabolic bone assessment in patients with inflammatory bowel disease. Gastroenterology 1995, 108:417-422

63. Pepe J, Zawadynski S, Herrmann FR, Juillerat P, Michetti P, FerrariLacraz S, Belli D, Ratib O, Rizzoli R, Chevalley T, Ferrari SL: Structural basis of bone fragility in young subjects with inflammatory bowel disease: a high-resolution pQCT study of the SWISS IBD cohort (SIBDC). Inflamm Bowel Dis 2017, 23:1410-1417

64. Liu H, Leslie EJ, Jia Z, Smith T, Eshete M, Butali A, Dunnwald M, Murray J, Cornell RA: Irf6 directly regulates Klf17 in zebrafish periderm and Klf4 in murine oral epithelium, and dominant-negative KLF4 variants are present in patients with cleft lip and palate. Hum Mol Genet 2016, 25:766-776

65. Romero-Barrios N, Legascue MF, Benhamed M, Ariel F, Crespi M: Splicing regulation by long noncoding RNAs. Nucleic Acids Res 2018, 46:2169-2184

66. Emadi E, Akhoundi F, Kalantar SM, Emadi-Baygi M: Predicting the most deleterious missense nsSNPs of the protein isoforms of the human HLA-G gene and in silico evaluation of their structural and functional consequences. BMC Genet 2020, 21:1-27

67. Yu CH, Dang Y, Zhou Z, Wu C, Zhao F, Sachs MS, Liu Y: Codon usage influences the local rate of translation elongation to regulate cotranslational protein folding. Mol Cell 2015, 59:744-754

68. Li MJ, Yan B, Sham PC, Wang J: Exploring the function of genetic variants in the non-coding genomic regions: approaches for identifying human regulatory variants affecting gene expression. Brief Bioinform 2014, 16:393-412 
69. Chu D, Wei L: Nonsynonymous, synonymous and nonsense mutations in human cancer-related genes undergo stronger purifying selections than expectation. BMC Cancer 2019, 19:359-370

70. Hernández M, Dutzan N, García-Sesnich J, Abusleme L, Dezerega A, Silva N, González FE, Vernal R, Sorsa T, Gamonal J: Host-pathogen interactions in progressive chronic periodontitis. J Dent Res 2011, 90: $1164-1170$

71. Pérez-Chaparro PJ, Gonçalves C, Figueiredo LC, Faveri M, Lobão E, Tamashiro N, Duarte P, Feres M: Newly identified pathogens associated with periodontitis: a systematic review. J Dent Res 2014, 93:846-858

72. Hong KW, Shin MS, Ahn YB, Lee HJ, Kim HD: Genome-wide association study on chronic periodontitis in Korean population: results from the Yangpyeong health cohort. J Clin Periodontol 2015, 42:703-710

73. Shimizu S, Momozawa Y, Takahashi A, Nagasawa T, Ashikawa K, Terada Y, Izumi Y, Kobayashi H, Tsuji M, Kubo M, Furuichi Y: A genome-wide association study of periodontitis in a Japanese population. J Dent Res 2015, 94:555-561

74. Divaris K, Monda KL, North KE, Olshan AF, Reynolds LM, Hsueh WC, Lange EM, Moss K, Barros SP, Weyant RJ, Liu Y, Newman AB, Beck JD, Offenbacher S: Exploring the genetic basis of chronic periodontitis: a genome-wide association study. Hum Mol Genet 2013, 22:2312-2324

75. Teumer A, Holtfreter B, Völker U, Petersmann A, Nauck M, Biffar R, Völzke H, Kroemer HK, Meisel P, Homuth G, Kocher T: Genomewide association study of chronic periodontitis in a general German population. J Clin Periodontol 2013, 40:977-985

76. Chen CY, Liu YJ, Shi SG, Chen FM, Cai C, Li B, Wang J, Shi L, Li Y, Liu ZY, Niu ZY: Osteogenic differentiation of human periodontal ligament stem cells expressing lentiviral NEL-like protein 1. Int J Mol Med 2012, 30:863-869

77. Wang B, Wu Y, Yu H, Jiang L, Fang B, Guo Q: The effects of NELL on corticotomy-assisted tooth movement and osteogenesis in a rat model. Biomed Mater Eng 2018, 29:757-771

78. Zhang J, Chen Y, Xu J, Wang J, Li C, Wang L: Tissue engineering using 3D printed nano-bioactive glass loaded with NELL1 gene for repairing alveolar bone defects. Regen Biomater 2018, 5:213-220

79. Rye MS, Warrington NM, Scaman ESH, Vijayasekaran S, Coates HL, Anderson D, Pennell CE, Blackwell JM, Jamieson SE: Genome-wide association study to identify the genetic determinants of otitis media susceptibility in childhood. PLoS One 2012, 7:e48215
80. Coker TR, Chan LS, Newberry SJ, Limbos MA, Suttorp MJ, Shekelle PG, Takata GS: Diagnosis, microbial epidemiology, and antibiotic treatment of acute otitis media in children: a systematic review. JAMA 2010, 304:2161-2169

81. Daly KA, Hoffman HJ, Kvaerner KJ, Kvestad E, Casselbrant ML, Homoe P, Rovers MM: Epidemiology, natural history, and risk factors: panel report from the Ninth International Research Conference on Otitis Media. Int J Pediatr Otorhinolaryngol 2010, 74: 231-240

82. Allen EK, Manichaikul A, Chen WM, Rich SS, Daly KA, Sale MM: Evaluation of replication of variants associated with genetic risk of otitis media. PLoS One 2014, 9:e104212

83. Hirsch FR, Scagliotti GV, Mulshine JL, Kwon R, Curran WJ, Wu YL, Paz-Ares L: Lung cancer: current therapies and new targeted treatments. Lancet 2017, 389:299-311

84. Zhang L, Villafranca A, Karl L, Kamal S, Torres B, Connor MO, Evers AS, Gradwohl S, Lin N, Palanca BJ: Activating mutations in the epidermal growth factor receptor underlying responsiveness of non-small-cell lung. N Engl J Med 2004, 350:2129-2139

85. Zhai Y, Wei R, Sha S, Lin C, Wang H, Jiang X, Liu G: Effect of NELL1 on lung cancer stem-like cell differentiation. Oncol Rep 2019, 41:1817-1826

86. Chen H, Zhang Z, Zhang L, Wang J, Zhang M, Zhu B: miR-27a protects human mitral valve interstitial cell from TNF- $\alpha$-induced inflammatory injury via up-regulation of NELL-1. Braz J Med Biol Res 2018, 51:e6997

87. Galesloot TE, Verweij N, Traglia M, Barbieri C, Van F, GeurtsMoespot AJ, Girelli D, Kiemeney LALM, Sweep FCGJ, Swertz MA, Van Der Meer P, Camaschella C, Toniolo D, Vermeulen SH, Van Der Harst P, Swinkels DW: Meta-GWAS and meta-analysis of exome array studies do not reveal genetic determinants of serum hepcidin. PLoS One 2016, 11:e0166628

88. Guénard F, Bouchard-Mercier A, Rudkowska I, Lemieux S, Patrick C, Vohl M-C: Genome-wide association study of dietary pattern scores. Nutrients 2017, 9:649-667

89. Baumert J, Huang J, Mcknight B, Sabater-lleal M, Steri M, Chu AY, et al: No evidence for genome-wide interactions on plasma fibrinogen by smoking, alcohol consumption and body mass index: results from meta-analyses of 80607 subjects. PLoS One 2014, 9: e111156 